\title{
Experimental Study and Identification of Optimal Cutting Parameters on Cutting Forces in Turning Using Taguchi Based Fuzzy Logic
}

\author{
Y.Poornachandra Sekhar ${ }^{1}$, S.M.Saleemuddin ${ }^{2}$, P. Meramma ${ }^{3}$ \\ ${ }^{1 \& 2}$ (Dept. of Mechanical Engineering, AITS, Rajampet-516172, Andhra Pradesh, India) \\ ${ }^{3}$ (Dept. of Mechanical Engineering, KSRM College of Engineering,Kadapa-516002, Andhra Pradesh, India)
}

\begin{abstract}
The cutting forces generated in turning are mainly influenced by speed, feed, depth of cut and tool geometry. The study of cutting forces for changes in tool geometry and feed rate using Taguchi Method and Fuzzy Logic is presented in this paper. Design of Experiments (DOE) helped in reducing the number of experiments to be performed. For an L16 orthogonal array DOE at different feed rates the turning experiments are performed on Aluminum rod with the HSS cutting tools by varying the tools of different rake angles at different approach angles and the values of responses (cutting forces) are tabulated. The analysis of the influence of feed rate and tool geometry on cutting forces is carried out by Taguchi and ANOVA methods and the optimal values of these factors are identified. A Taguchi based Fuzzy Logic system is developed using Taguchi experimental results. The cutting forces are estimated with the help of Fuzzy Logic system for the optimal values of feed rate and tool geometry. The prediction error is calculated for fuzzy results and is about 2.78 and the percentage of accuracy is $97.22 \%$.
\end{abstract}

Keywords: Taguchi method; tool geometry, cutting forces, feed rate, Analysis of variance, fuzzy inference system;

\section{Introduction}

The quality is an emerging challenge of modern machining industries the achievement of high quality in terms of work piece dimensional accuracy, surface finish, high production rate, less wear on the cutting tools, economy in machining is difficult task. The analysis of cutting forces is necessary for design and evaluation of machining parameters, tool design and calculation of power requirements etc. The cutting forces are mainly influenced by depth of cut and feed rate, respectively more than by cutting speed [1]. The cutting force components are very sensitive even for the smallest changes in the cutting process. Therefore, instead of calculating the cutting force theoretically, measuring them in process by dynamometers is preferred [2].

a. Feed rate

The feed rate is the amount of tool advancement per revolution of job parallel to the surface being machined and is measured in $\mathrm{mm} / \mathrm{revolution}$. Feed rate is effective on all cutting forces, in the case of increasing feed rate, especially feed force increases and residual stresses change from compressive to tensile [3].

\section{b. Tool geometry}

Rake angle $(\alpha)$ is the angle contained by a plane perpendicular to the main cutting edge of the tool and is a measure of the edge in relation to the cut itself. This angle can be take positive or negative value. Positive rake angle produces higher shear angle and therefore, it leads to reduction of cutting forces. But excessive value of this angle causes tool breakage [4]. Negative rake angle strengthens tool edge against hammering effects and heavy machining loads. In contrast the tools having positive rake (negative rake) tools produce high specific cutting pressure consequently high cutting forces.

Approaching angle $(k)$ is the angle at which cutting tool enters and leaves the cutting zone. The chip cross-section is determined by the approaching angle, but it has a relatively low influence on the cutting forces. Since the main cutting edge enters and leaves cutting zone suddenly at $90^{\circ}$ of approaching angle it is subjected to maximum loading and unloading. When the tool is fed along a line at $90^{\circ}$ to the axis of work-piece, namely cutting action is orthogonal [5]. In oblique cutting, approaching angle is $0^{0}<\mathrm{k}<90^{\circ}$. The tool geometry is given in Fig1(a). 


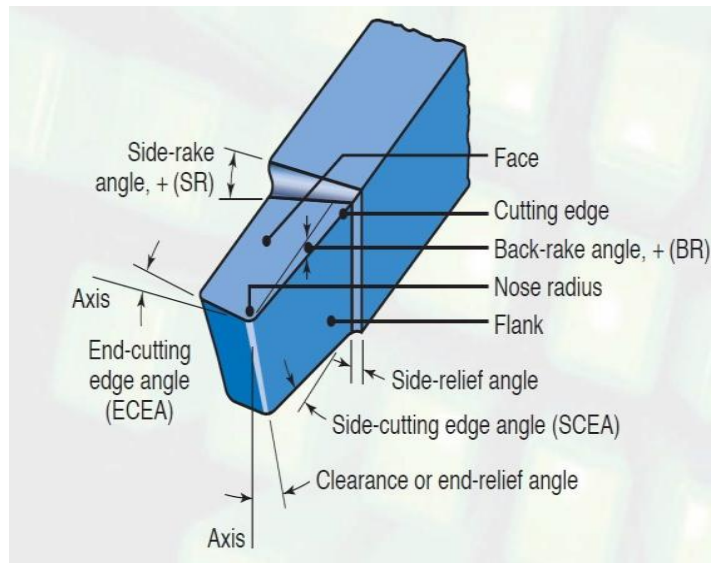

(a)

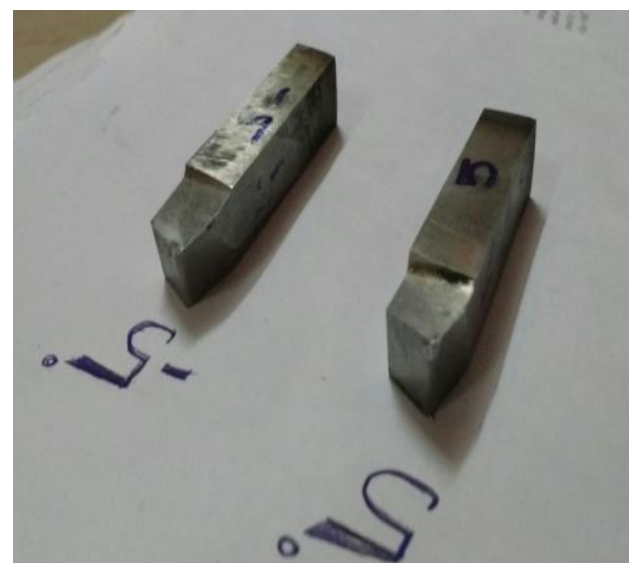

(b)

Fig. 1(a) Tool geometry of Cutting tool; (b) Cutting tools with rake angles.

The objective of this Paper is to analyze the influence of feed rate, rake angle and approach angle on cutting forces. And to determine, the optimized feed rates and tool angles with reference to cutting forces.

\section{Input Factors and Taguchi Design of Experiments}

The factors and their levels are summarized in Table 1.

Table 1: Factors and factor levels

\begin{tabular}{|l|l|lllll|}
\hline \multicolumn{1}{|c|}{ Controllable factors } & Symbol & \multicolumn{4}{c|}{ Factor levels } \\
\hline Rake Angle (degree) & $\boldsymbol{\alpha}$ & $-5^{0}$ & $5^{0}$ & & \\
\hline Approach Angle ( degree) & $\boldsymbol{k}$ & $45^{0}$ & $60^{0}$ & $75^{0}$ & $90^{0}$ \\
\hline Feed rate (mm/rev) & $\boldsymbol{f}$ & 0.16 & 0.20 & 0.25 & 0.32 \\
\hline
\end{tabular}

For three-factor Mixed-level, a Taguchi design orthogonal array L16 experimental design is selected (Table 2) to conduct the experiments and to record the responses.

Table 2. Design of experiments (Taguchi L16).

\begin{tabular}{|l|l|l|l|}
\hline $\begin{array}{l}\text { Exp. } \\
\text { No. }\end{array}$ & $\begin{array}{l}\text { Rake Angle } \\
(\boldsymbol{\alpha})\end{array}$ & $\begin{array}{l}\text { Approach Angle } \\
(\boldsymbol{k})\end{array}$ & $\begin{array}{l}\text { Feed Rate } \\
(\boldsymbol{f})\end{array}$ \\
\hline 1 & -5 & 75 & 0.16 \\
\hline 2 & -5 & 75 & 0.20 \\
\hline 3 & -5 & 90 & 0.16 \\
\hline 4 & -5 & 90 & 0.20 \\
\hline 5 & -5 & 60 & 0.25 \\
\hline 6 & -5 & 60 & 0.32 \\
\hline 7 & -5 & 45 & 0.25 \\
\hline 8 & -5 & 45 & 0.32 \\
\hline 9 & 5 & 75 & 0.16 \\
\hline 10 & 5 & 75 & 0.20 \\
\hline 11 & 5 & 90 & 0.16 \\
\hline 12 & 5 & 90 & 0.20 \\
\hline 13 & 5 & 60 & 0.25 \\
\hline 14 & 5 & 60 & 0.32 \\
\hline 15 & 5 & 45 & 0.25 \\
\hline 16 & 5 & 45 & 0.32 \\
\hline
\end{tabular}

\section{Experimental Work}

The turning experiments are performed according to Taguchi experimental design given in Table 2, on Aluminum work-piece of size $\Phi 36 \times 100 \mathrm{~mm}$ with different HSS cutting tools having different rake angles $\left(-5^{0}\right.$ and $\left.5^{\circ}\right)$ at different approach angles $\left(45^{\circ}, 60^{\circ}, 75^{\circ}\right.$ and $\left.90^{\circ}\right)$ and with different feed rates $(0.16,0.20,0.25$ and 0.32 ) at dry cutting conditions on PSG A141 conventional lathe. The experimental setup is shown in Fig.2. All the turning experiments are conducted at a constant speed of $v_{\mathrm{c}}=450 \mathrm{rev} / \mathrm{min}$ and depth of cut $=1 \mathrm{~mm}$. 


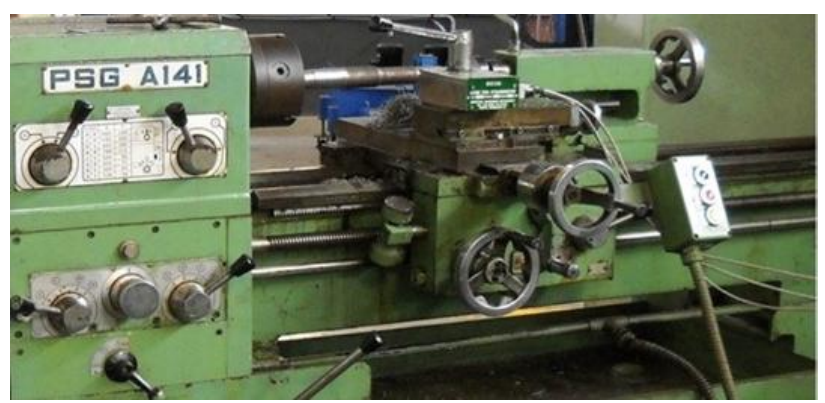

Fig. 2 (a) Experimental setup;

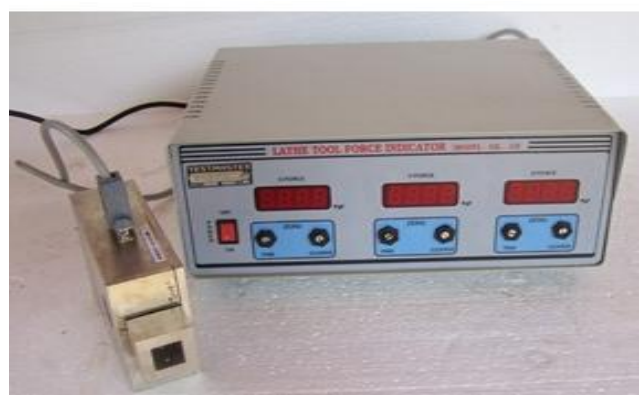

(b) Lathe tool force indicator.

Cutting forces are measured with a three-component compact force dynamometer shown in Fig.3(b) and transferred from over serial port to the PC directly for further evaluation. The cutting forces namely feed force $\left(F_{f}\right)$, Cutting force $\left(F_{c}\right)$ and Radial force $\left(F_{r}\right)$ are recorded in Table 3.

Table 3. Experimental data.

\begin{tabular}{|l|l|l|l|l|l|l|}
\hline & \multicolumn{3}{|c|}{ Input Parameters } & \multicolumn{3}{c|}{ Cutting forces } \\
\hline Exp. No. & $\boldsymbol{A}$ & $\boldsymbol{k}$ & $\boldsymbol{f}$ & $\boldsymbol{F}_{\boldsymbol{f}}$ & $\boldsymbol{F}_{\boldsymbol{c}}$ & $\boldsymbol{F}_{\boldsymbol{r}}$ \\
\hline 1 & -5 & 75 & 0.16 & 88 & 90 & 40 \\
\hline 2 & -5 & 75 & 0.20 & 108 & 120 & 50 \\
\hline 3 & -5 & 90 & 0.16 & 157 & 40 & 190 \\
\hline 4 & -5 & 90 & 0.20 & 127 & 60 & 230 \\
\hline 5 & -5 & 60 & 0.25 & 90 & 140 & 40 \\
\hline 6 & -5 & 60 & 0.32 & 100 & 160 & 50 \\
\hline 7 & -5 & 45 & 0.25 & 87 & 150 & 30 \\
\hline 8 & -5 & 45 & 0.32 & 112 & 160 & 50 \\
\hline 9 & 5 & 75 & 0.16 & 98 & 100 & 210 \\
\hline 10 & 5 & 75 & 0.20 & 108 & 110 & 210 \\
\hline 11 & 5 & 90 & 0.16 & 98 & 30 & 150 \\
\hline 12 & 5 & 90 & 0.20 & 110 & 50 & 180 \\
\hline 13 & 5 & 60 & 0.25 & 118 & 140 & 130 \\
\hline 14 & 5 & 60 & 0.32 & 157 & 160 & 140 \\
\hline 15 & 5 & 45 & 0.25 & 122 & 150 & 90 \\
\hline 16 & 5 & 45 & 0.32 & 127 & 170 & 100 \\
\hline
\end{tabular}

\section{Analysis of Cutting Forces Using Taguchi And ANOVA}

\section{a. Taguchi Analysis}

Taguchi has significant advantage in reduction of number of experiments to be performed to get necessary response functions at the stage of Design of Experiments (DOE). S/N ratio is used to measure the quality characteristic deviating from the desired value [6]. The term 'signal' represents the desirable value (mean) for the output characteristic and the term 'noise' represents the undesirable value for the output characteristic. In this study 'Smaller is Better' characteristic is used for calculation of S/N ratio and mean for getting the optimized cutting forces.

$$
\frac{\mathrm{S}}{\mathrm{N}}{ }_{\text {(Smaller) }}=-10 \log \left[\sum_{\mathrm{i}=1}^{\mathrm{n}} \frac{\mathrm{y}_{\mathrm{i}}{ }^{2}}{n}\right]
$$

where, $\mathrm{y}_{\mathrm{i}}$ : Value of force component of dataset $i$.

$$
\mathrm{n} \text { : number of experiments. }
$$

Taguchi analysis for cutting forces $\left(F_{f}, F_{c}\right.$ and $\left.F_{r}\right)$ versus rake angle, approach angle and feed rate results S/N ratio and mean values are given in Table 4.

Table 4(a). Feed force $\left(F_{f}\right)$

\begin{tabular}{|l|l|l|l|l|l|l|l|l|}
\hline Level & $\boldsymbol{\alpha}$ & $\boldsymbol{k}$ & $\boldsymbol{f}$ & & Level & $\boldsymbol{\alpha}$ & $\boldsymbol{k}$ & $\boldsymbol{f}$ \\
\hline 1 & -40.55 & -40.89 & -40.61 & 1 & -40.36 & -43.93 & -35.17 \\
\hline 2 & -41.29 & -41.11 & -41.06 & 2 & -39.94 & -43.50 & -37.99 \\
\hline 3 & -42.51 & -40.01 & -40.26 & 3 & -41.22 & -40.37 & -43.22 \\
\hline 4 & -43.33 & -41.66 & -41.74 & 4 & -41.17 & -32.78 & -44.21 \\
\hline Delta & 0.74 & 1.65 & 1.48 & & Delta & 0.42 & 11.15 & 9.05 \\
\hline Rank & $\mathbf{3}$ & $\mathbf{1}$ & $\mathbf{2}$ & Rank & $\mathbf{3}$ & $\mathbf{1}$ & $\mathbf{2}$ \\
\hline
\end{tabular}


Table 4(c). Radial force $\left(F_{r}\right)$

\begin{tabular}{|l|l|l|l|}
\hline Level & $\boldsymbol{\alpha}$ & $\boldsymbol{k}$ & $\boldsymbol{f}$ \\
\hline 1 & -36.05 & -35.65 & -41.90 \\
\hline 2 & -43.23 & -37.81 & -43.19 \\
\hline 3 & -33.96 & -39.73 & -35.74 \\
\hline 4 & -34.81 & -45.36 & -37.72 \\
\hline Delta & 7.18 & 9.71 & 7.45 \\
\hline rank & $\mathbf{3}$ & $\mathbf{1}$ & $\mathbf{2}$ \\
\hline
\end{tabular}

The rank is determined based on influencing level of the corresponding parameter on the respective cutting force $\left(F_{f}, F_{c}\right.$ and $\left.F_{r}\right)$. The values optimum cutting factors for feed force, cutting force and radial force are given in below Table. 5

Table 5 .Ranks of influencing cutting parameters on cutting forces.

\begin{tabular}{|l|l|l|l|l|l|l|l|l|}
\hline \multicolumn{3}{|c|}{ Cutting force $\left(\boldsymbol{F}_{f}\right)$} & \multicolumn{3}{|c|}{ Cutting force $\left(\boldsymbol{F}_{\boldsymbol{c}}\right)$} & \multicolumn{3}{c|}{ Radial force $\left(\boldsymbol{F}_{\boldsymbol{r}}\right)$} \\
\hline Rank & Parameter & Value & Rank & Parameter & Value & Rank & Parameter & Value \\
\hline 1 & Rake angle & $5^{0}$ & 1 & Feed rate & 0.16 & 1 & Approach angle & $45^{0}$ \\
\hline 2 & Approach angle & $90^{0}$ & 2 & Approach angle & $90^{0}$ & 2 & Rake angle & $-5^{0}$ \\
\hline 3 & Feed rate & 0.32 & 3 & Rake angle & $5^{0}$ & 3 & Feed rate & 0.25 \\
\hline
\end{tabular}

The main effects plots for $\mathrm{S} / \mathrm{N}$ ratio are shown in Fig. 3. The main effect plot for feed force $\mathrm{S} / \mathrm{N}$ ratio graph shows that the optimum values of influencing factors in their rank order. According to SN ratio analysis the maximum point is the optimum influencing level of the cutting factor on corresponding cutting force.

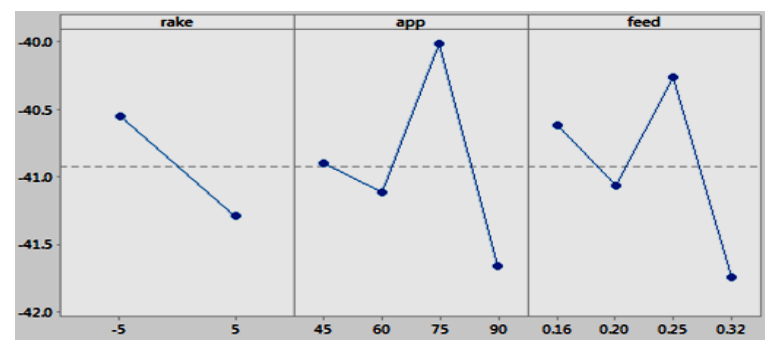

Fig. 3(a). The main effects plots for $\mathrm{S} / \mathrm{N}$ ratio $\mathrm{Vs} \mathrm{F}_{\mathrm{f}}$.

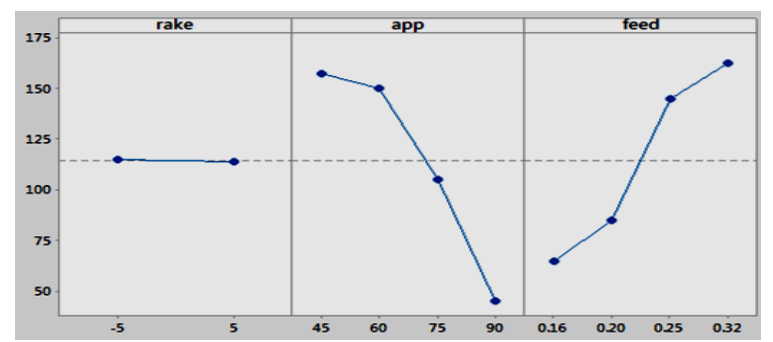

Fig. 3(b). The main effects plots for $\mathrm{S} / \mathrm{N}$ ratio $\mathrm{Vs} \mathrm{F}_{\mathrm{c}}$.

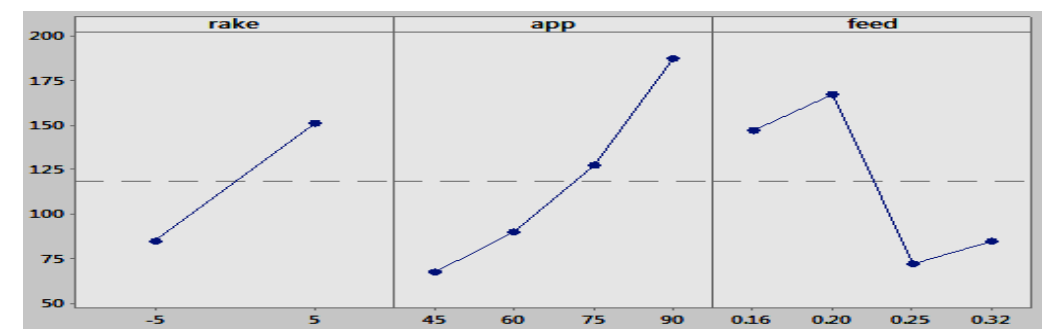

Fig. 3(c). The main effects plots for $\mathrm{S} / \mathrm{N}$ ratio Versus $\mathrm{F}_{\mathrm{r}}$

\section{b. Analysis of Variance (ANOVA)}

ANOVA is used for the single response; therefore the tests are conducted separately for each component of cutting forces. The cutting forces are evaluated by the $95 \%$ confidence level, this indicates that the obtained models are considered to be statistically significant and the terms in the model have a significant effect on the responses. The ANOVA results for experimental data are given in Table 3.

Table 5(a). ANOVA results for $F_{f}$.

\begin{tabular}{|l|l|l|l|l|l|l|}
\hline Source & DF & $\begin{array}{l}\text { Seq } \\
\text { SS }\end{array}$ & $\begin{array}{l}\text { Adj } \\
\text { SS }\end{array}$ & $\begin{array}{l}\text { Adj } \\
\text { MS }\end{array}$ & F & P \\
\hline$\alpha$ & 3 & 3292 & 3292 & 1097 & 0.61 & 0.631 \\
\hline$k$ & 3 & 361 & 362 & 121 & 0.07 & 0.975 \\
\hline$f$ & 3 & 1027 & 1027 & 342 & 0.19 & 0.899 \\
\hline Error & 6 & 10731 & 10731 & 1789 & & \\
\hline Total & 15 & 15412 & & & & \\
\hline
\end{tabular}

$\mathrm{S}=22.3814, \mathrm{R}-\mathrm{Sq}=19.90 \%, \mathrm{R}-\mathrm{Sq}(\mathrm{adj})=0.00 \%$ 


\begin{tabular}{|l|l|l|l|l|l|l|}
\multicolumn{8}{c}{5 (b). ANOVA results for $\boldsymbol{F}_{\boldsymbol{c}}$. } \\
\begin{tabular}{|l|l|l|l|l|l|l|}
\hline Source & DF & $\begin{array}{l}\text { Seq } \\
\text { SS }\end{array}$ & $\begin{array}{l}\text { Adj } \\
\text { SS }\end{array}$ & $\begin{array}{l}\text { Adj } \\
\text { MS }\end{array}$ & F & P \\
\hline$\alpha$ & 3 & 10794 & 10794 & 3598 & 1.64 & 0.277 \\
\hline$k$ & 3 & 10918 & 10918 & 3639 & 1.66 & 0.273 \\
\hline$f$ & 3 & 13395 & 13395 & 4465 & 2.03 & 0.211 \\
\hline Error & 6 & 13166 & 13166 & 2194 & & \\
\hline Total & 15 & 48274 & & & & \\
\hline
\end{tabular} \\
\hline
\end{tabular}

Table 5(c). ANOVA results for $F_{r}$.

\begin{tabular}{|l|l|l|l|l|l|l|}
\hline Source & DF & Seq SS & Adj SS & Adj MS & F & P \\
\hline$\alpha$ & 3 & 20812.2 & 20812.2 & 6937.4 & 12.86 & 0.005 \\
\hline$k$ & 3 & 34307.2 & 34307.2 & 11435.7 & 21.20 & 0.001 \\
\hline$f$ & 3 & 15747.7 & 15747.7 & 5249.2 & 9.73 & 0.010 \\
\hline Error & 6 & 3236.9 & 3236.9 & 539.5 & & \\
\hline Total & 15 & 74103.9 & \multicolumn{7}{|c|}{} & & \\
\hline \multicolumn{7}{|c|}{$\mathrm{S}=47.1639, \mathrm{Sq}=67.39 \%$} \\
\hline
\end{tabular}

p-test:

The $\mathrm{p}$ values helps in identification of the significant difference of most effecting factors. From ANOVA probability test ( $\mathrm{p}$ test), if $\mathrm{p}>0.05$ then there is no significant difference and if $\mathrm{p}<0.05$ then there is a significant difference from their group. The ANOVA results shown in Table 5 , reveals that factors of feed force are having $p$ values $0.457,0.564$ and 2.900 i.e, $p>0.05$; hence there is no significant difference. Similarly cutting force factors are having $p$ values $0.843,0.000$ and 0.21 i.e, $p>0.05$ so these factors are also not showing any significant difference. But the $\mathrm{p}$ values of radial force factors are 0.017, $0.021,0.034$ (i.e, $\mathrm{p}<0.05$ ); there is significant difference from this group.

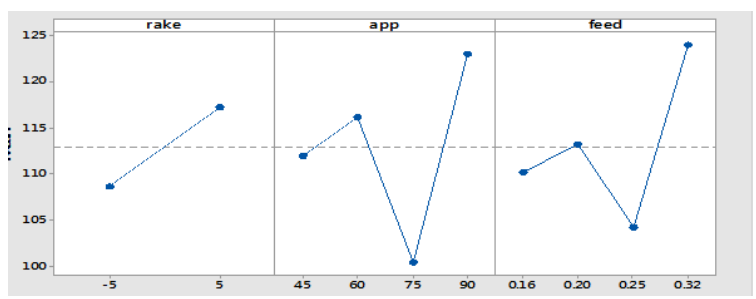

Fig. 4 (a) Main effects plot for $F_{f}$

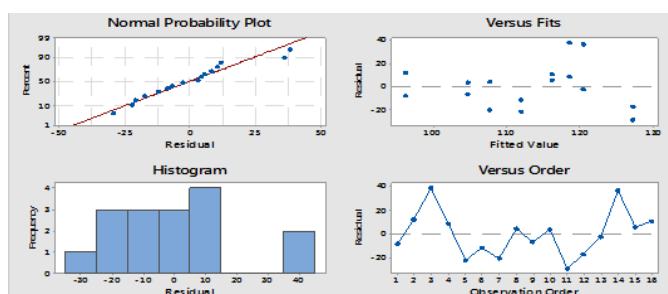

Fig. 4 (b) Residual plots for $F_{f}$.

The normality plot of the residuals above shows that the residuals follow a normal distribution. Both plot of residuals versus fitted values and plot of residuals versus run order do not show any pattern. Thus, both constant variance and independence assumptions are satisfied. The main effects plot and interaction plot for Feed force $\left(F_{f}\right)$ are shown in Fig 4. From the ANOVA results table adjusted sum of squares (Adj SS) and their total sum of squares (SS) on each individual response or cutting force, which can help in finding out of the percentage of influence values of the factors; to evaluate the significance of the corresponding factors. The Percentage of influence equation is given by

$\%$ of influence $=\frac{\operatorname{AdjSS}}{\text { Total SS }} \times 100$

The most effective factor on $F_{f}$ is rake angle, on $F_{c}$ is feed rate and for $F_{r}$ is approach angle. According to ANOVA statistical significant analysis these factors are most influencing on cutting forces hence these are considered to be non-significant. The percentage of influence charts, on cutting forces by rake angle(1), Approach angle(2) and feed rate(3) are shown in Fig 5. 


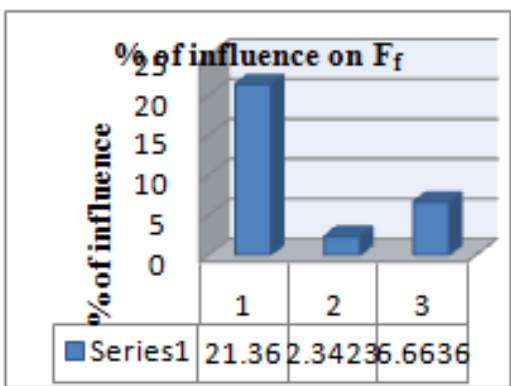

Fig 5. (a) $\%$ of influence chart on $F_{f}$;

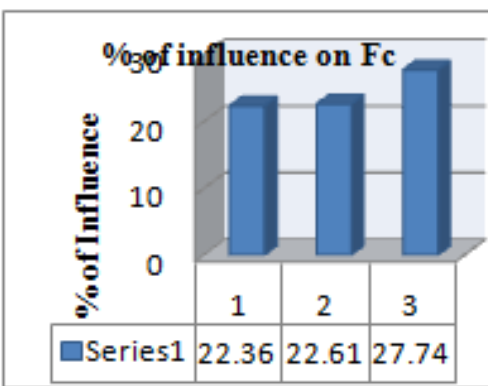

(b) $\%$ of influence chart on $F_{c}$;

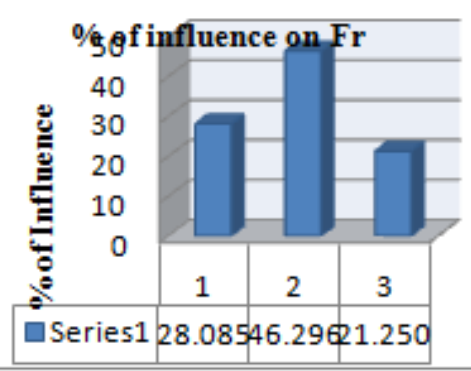

(c) $\%$ of influence chart on $F_{r}$.

\section{Taguchi Based Fuzzy Logic}

Fuzzy Logic inference system involves in the process of mapping from a given input to an output using fuzzy logic. The process of fuzzy inference involves the following elements: Membership Functions, Logical Operations, and If-THEN Rules. Fuzzy sets and logic is a discipline that has proved itself successful in automated reasoning of expert systems [7]. The set of fuzzy rules defines a fuzzy estimation surface. The accuracy of interpolation depends on the number of Membership Functions (MF), their position, their shape and the rules used to express the relationships between these membership functions. Here Mamdani max-min interference for interference mechanism and centre of gravity (Centroid) defuzzier formula method for defuzzification are used, because these operators assure a linear interpolation of output between the rules. The structure of fuzzy system is shown in Fig 6.

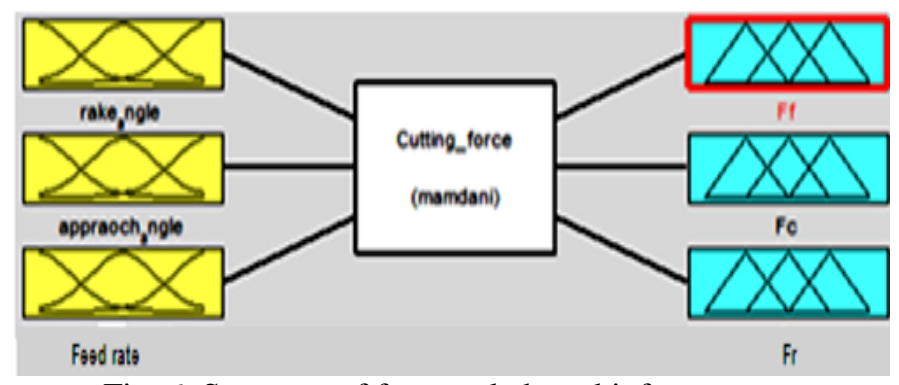

Fig. 6 Structure of fuzzy rule based inference system.

\section{a. Fuzzy sets and Membership Functions (MF)}

The range of input and output variables were divided into fuzzy sets as linguistic variable in the next step. These membership functions helped converting to numeric variables into linguistic terms. Four fuzzy sets are designed for each input $(\alpha, k$ and $f)$ and output $\left(F_{f}, F_{c}\right.$ and $\left.F_{r}\right)$ variables. For the input variables, equally distributed curve 'triangular' membership function and for the output variables, equally distributed curve 'guass' membership function fuzzy sets are utilized. The linguistic terms used in input fuzzy sets are 'Low', 'High', 'MLow', and 'MHigh'. The values of input factors and corresponding linguistic terms are summarized in Table 6.

Table 6.Expressions used in fuzzy sets of $F_{f}, F_{c}$ and $F_{r}$.

\begin{tabular}{|l|l|l|l|l|l|}
\hline $\boldsymbol{\alpha}$ & MF name & $\boldsymbol{k}$ & MF name & $\boldsymbol{F}$ & MF name \\
\hline-5 & Low & 45 & Low & 0.16 & Low \\
\hline & & 60 & M Low & 0.20 & M Low \\
\hline 5 & High & 75 & High & 0.25 & High \\
\hline & & 90 & M High & 0.32 & M High \\
\hline
\end{tabular}

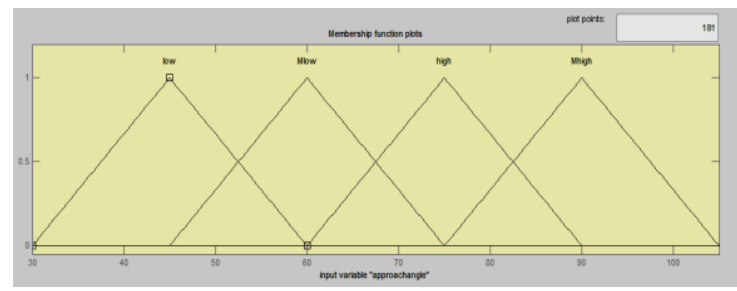

Fig. 7 (a) Membership functions for approach angle.

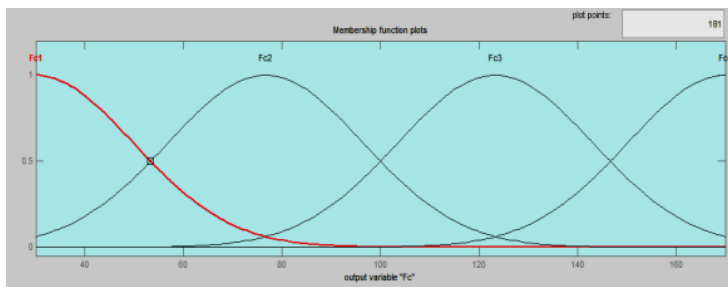

(b) Membership functions for $F_{f}$. 
b. Fuzzy rules

\begin{tabular}{|c|c|c|c|c|c|c|}
\hline \multirow[b]{2}{*}{ Sno } & \multirow{2}{*}{$\begin{array}{c}\text { Rake } \\
\text { angle(a) }\end{array}$} & \multirow{2}{*}{$\begin{array}{l}\text { Approach } \\
\text { angles (k) }\end{array}$} & \multirow{2}{*}{$\begin{array}{c}\text { Feed rate } \\
\text { (f) }\end{array}$} & \multicolumn{3}{|c|}{ Cutting forces } \\
\hline & & & & $F_{f}$ & $F_{a}$ & $F_{r}$ \\
\hline 1 & Low & High & Low & Fc2 & Ff1 & Fr1 \\
\hline 2 & Low & High & Mlow & Fc3 & Ff2 & Fr1 \\
\hline 3 & Low & MHigh & Low & $\mathrm{Fc1}$ & $\mathrm{Ff} 4$ & Fr4 \\
\hline 4 & Low & MHigh & Mlow & $\mathrm{Fc1}$ & Ff3 & Fr4 \\
\hline 5 & Low & Mlow & High & $\mathrm{Fc1}$ & Ff1 & Fr1 \\
\hline 6 & Low & Mlow & M High & Fc4 & Ff1 & Fr1 \\
\hline 7 & Low & Low & High & Fc4 & $\mathrm{Ff} 2$ & Fr1 \\
\hline 8 & Low & Low & MHigh & $\mathrm{Fc4}$ & Ff1 & Fr1 \\
\hline 9 & High & High & Low & $\mathrm{Fc} 2$ & Ff 2 & Fr4 \\
\hline 10 & High & High & Mlow & $\mathrm{Fc} 3$ & Ff1 & Fr4 \\
\hline 11 & High & MHigh & Low & Fc1 & Ff 2 & Fr4 \\
\hline 12 & High & MHigh & Mlow & $\mathrm{Fc1}$ & Ff 2 & Fr4 \\
\hline 13 & High & Mlow & High & Fc4 & $\mathrm{Ff} 2$ & Fr3 \\
\hline 14 & High & Mlow & MHigh & Fc4 & Ff4 & Fr3 \\
\hline 15 & High & Low & High & Fc4 & Ff 2 & $\mathrm{Fr} 2$ \\
\hline 16 & High & Low & M High & Fc4 & Ff3 & $\mathrm{Fr} 2$ \\
\hline
\end{tabular}

\begin{tabular}{|c|c|c|c|c|c|}
\hline \multicolumn{3}{|c|}{ Input Factors } & \multicolumn{3}{|c|}{ Fuzzy results } \\
\hline $\boldsymbol{a}$ & $\boldsymbol{k}$ & $F$ & $\overline{F_{f}}$ & $\vec{F}_{6}$ & $F_{r}$ \\
\hline-5 & 75 & 0.16 & 100 & 122 & 130 \\
\hline-5 & 75 & 0.20 & 77.1 & 94.7 & 52 \\
\hline-5 & 90 & 0.16 & 100 & 122 & 130 \\
\hline-5 & 90 & 0.20 & 45.4 & 150 & 208 \\
\hline-5 & 60 & 0.25 & 148 & 97.9 & 61 \\
\hline-5 & 60 & 0.32 & 155 & 94.7 & 52 \\
\hline-5 & 45 & 0.25 & 148 & 111 & 61 \\
\hline-5 & 45 & 0.32 & 155 & 94.7 & 52 \\
\hline 5 & 75 & 0.16 & 100 & 122 & 130 \\
\hline 5 & 75 & 0.20 & 77.1 & 111 & 208 \\
\hline 5 & 90 & 0.16 & 100 & 122 & 130 \\
\hline 5 & 90 & 0.20 & 45.4 & 111 & 208 \\
\hline 5 & 60 & 0.25 & 148 & 111 & 162 \\
\hline 5 & 60 & 0.32 & 155 & 150 & 162 \\
\hline 5 & 45 & 0.25 & 148 & 111 & 98.2 \\
\hline 5 & 45 & 0.32 & 155 & 134 & 97.3 \\
\hline
\end{tabular}

The relationship between inputs and output in a fuzzy system is characterized by set of linguistic statements which are called fuzzy rules. The number of fuzzy rules in a fuzzy system is related to the number of fuzzy sets for each input variable. Expressions and the abbreviation details of these fuzzy sets, giving minimum values of estimation error for 16 possible rules, are provided in Table 7.

The estimated values for all the three cutting forces $\left(F_{f}, F_{c}\right.$ and $\left.F_{r}\right)$ are obtained by the rule viewer and are shown in Table 8.

Note: The optimal values of feed force $\left(\boldsymbol{F}_{f}\right)$, cutting force $\left(\boldsymbol{F}_{c}\right)$ and radial force $\left(\boldsymbol{F}_{\boldsymbol{r}}\right)$ for $\alpha=-5^{0}, k=45^{0}$ and $f=$ $0.25 \mathrm{~mm} / \mathrm{rev}$, which are optimal cutting parameters of Taguchi analysis are $148 \mathrm{~kg}$, $111 \mathrm{~kg} f$ and $61 \mathrm{~kg} f$, respectively.

\section{c. Testing and Comparison}

In order to compare the estimated cutting forces from the fuzzy rule based system with the actual experimental data three sample data sets were selected (Optimal cutting parameters in Taguchi analysis). The Prediction error $\left(e_{p}\right)$ test is conducted for selected datasets [8]. The results are shown in Table 9.

$\mathrm{e}_{\mathrm{p}}=\frac{1}{\mathrm{n}}\left[\sum_{\mathrm{i}=1}^{\mathrm{n}}\left(\mathrm{F}_{\mathrm{ev}}-\mathrm{F}_{\mathrm{fv}}\right)\right]$

Table 9. Prediction error test results.

\begin{tabular}{|l|l|l|l|l|l|l|l|l|}
\hline \multicolumn{3}{|l|}{ Optimal combinations } & \multicolumn{2}{l|}{ Fuzzy values $\left(\mathbf{F}_{\mathbf{f v}}\right)$} & \multicolumn{2}{l|}{ Experimental values( $\left.\mathbf{F}_{\text {ev }}\right)$} \\
\hline $\boldsymbol{\alpha}$ & $\boldsymbol{k}$ & $\boldsymbol{f}$ & $\boldsymbol{F}_{\boldsymbol{f}}$ & $\boldsymbol{F}_{\boldsymbol{c}}$ & $\boldsymbol{F}_{\boldsymbol{r}}$ & $\boldsymbol{F}_{\boldsymbol{f}}$ & $\boldsymbol{F}_{\boldsymbol{c}}$ & $\boldsymbol{F}_{\boldsymbol{r}}$ \\
\hline 5 & 90 & 0.16 & 122 & 100 & 130 & 117 & 99 & 128 \\
\hline 5 & 90 & 0.32 & 122 & 100 & 100 & 118 & 100 & 94 \\
\hline-5 & 45 & 0.25 & 111 & 148 & 61 & 105 & 144 & 64 \\
\hline
\end{tabular}

If the cutting tools undergoes changing of tool geometry due to possible tool wear or tool breakage the abnormal increase in wear would be reported by increase in cutting force. This proves that fuzzy logic technique incorporating cutting forces as major input can be used to diagnose tool wear states in tool condition monitoring systems.

\section{Conclusions}

The optimal values of feed rate, rake angle and approach angle are identified for optimum cutting forces in turning using Taguchi Method. The percentage of influence of cutting parameters on cutting forces also determined with the help of Analysis of variance (ANOVA). From the results of this work the following conclusions are drawn:

- The Fuzzy Logic results the estimated values of cutting forces for designed model of experimental data set and the values of feed force $\left(\mathrm{F}_{\mathrm{f}}\right)$, cutting force $\left(\mathrm{F}_{\mathrm{c}}\right)$ and radial force $\left(\mathrm{F}_{\mathrm{r}}\right)$ for $\alpha=-5^{0}, k=45^{0}$ and $f=0.25$ $\mathrm{mm} / \mathrm{rev}$ were obtained as $148 \mathrm{kgf}, 111 \mathrm{kgf}$ and $61 \mathrm{kgf}$, respectively. 
- On comparison of fuzzy results with actual experimental values for optimized data sets, the prediction error is found to be about 2.78 and percentage of accuracy is $97.22 \%$.

\section{References}

[1]. Nicoleta LUNGU, Marian BORZAN, "Effect of cutting speed and feed rate on tool geometry, Temperature and cutting forces in machining AISI 1045 carbon steel Using fem simulation”, Proceedings in Manufacturing Systems, Volume 7, Issue 4, pp 245-252, 2012.

[2]. Saglam, H., Yaldiz, S., Unsacar, F, "The effect of tool geometry and cutting speed on main cutting force and tool tip temperature", Materials and Design, 28, 101-111, 2007.

[3]. Thiele, J.D., Melkote, S.N., Peascoe, R.A., Watkins, T.R, "Effect of cutting-edge geometry and work piece hardness on surface residual stresses in finish hard turning of AISI 52100 steel”, ASME Journal of Manufacturing Science and Engineering, 122, 642-649, 2000.

[4]. HacıSağlam, "Analysis of the influences of feed rate and tool geometry on cutting forces using regression analysis and fuzzy logic in turning", Journal of Technical-Online, Vol; 10, Issue 2, 136-155, 2011.

[5]. Satyanarayana.Kosaraju, VenuGopal. Anne and VenkateswaraRao.Ghanta, "Effect of Rake Angle and Feed Rate on Cutting Forces in an Orthogonal Turning Process", International Conference on Trends in Mechanical and Industrial Engineering (ICTMIE'2011) Bangkok, 150-154, Dec., 2011.

[6]. Rama Rao S, Padmanabhan G, "Application of Taguchi methods and ANNOVA in optimization of process parameters for metal removal rate in electrochemical machining of AL/5\%SiC Composites", International Journal of Engineering Research and Application, 2,pp 192-197, 2012.

[7]. Hashmi, K., Graham, I. D., \& Mills. B, "Data selection for turning carbon steelusing a fuzzy logic approach”, Journal of Material Processing Technology, 135, 44-58, 2003.

[8]. P.Venkataramaiah, K.DharmaReddy, P. Meramma, "Analysis on Influence of feed rate and tool geometry on cutting forces in turning using Taguchi method and Fuzzy Logic", International Conference on Advances in Manufacturing and Materials Engineering, Vol 5, Pages 1692-1701, 2014. 